\title{
microRNA mir-598-3p mediates susceptibility to stress enhancement of remote fear memory
}

\author{
Meghan E. Jones, ${ }^{1,2,3}$ Stephanie E. Sillivan, ${ }^{1,2,3}$ Sarah Jamieson,, ${ }^{1,2}$ Gavin Rumbaugh, ${ }^{2}$ \\ and Courtney A. Miller ${ }^{1,2}$ \\ ${ }^{1}$ Department of Molecular Medicine; ${ }^{2}$ Department of Neuroscience, The Scripps Research Institute, Jupiter, Florida 33458, USA
}

\begin{abstract}
microRNAs (miRNAs) have emerged as potent regulators of learning, recent memory, and extinction. However, our understanding of miRNAs directly involved in regulating complex psychiatric conditions perpetuated by aberrant memory, such as in posttraumatic stress disorder (PTSD), remains limited. To begin to address the role of miRNAs in persistent memories, we performed small-RNA sequencing on basolateral amygdala (BLA) tissue and identified miRNAs altered by auditory fear conditioning (FC) one month after training. mir-598-3p, a highly conserved miRNA previously unstudied in the brain, was down-regulated in the BLA. Further decreasing BLA mir-598-3p levels did not increase strength of the remote fear memory. Given that stress is a critical component in PTSD, we next assessed the impact of stress and stress-enhanced fear learning (SEFL) on mir-598-3p levels, finding the miRNA is elevated in the BLA of male, but not female, mice susceptible to the effects of stress in SEFL. Accordingly, intra-BLA inhibition of mir-598-3p interfered with expression and extinction of the remote fear memory in male, but not female, mice. This effect could not be attributed to an anxiolytic effect of miRNA inhibition. Finally, bioinformatic analysis following quantitative proteomics on BLA tissue collected $30 \mathrm{~d}$ post-SEFL training identified putative mir-598-3p targets and related pathways mediating the differential susceptibility, with evidence for regulation of the actin cytoskeleton, the core mediator of structural plasticity. Taken together, the results suggest BLA mir-598-3p may be recruited by stress to mediate a critical switch from a salient remote fear memory to one that is enhanced and extinction-resistant.
\end{abstract}

[Supplemental material is available for this article.]

Persistent, maladaptive long-term memories are a characteristic feature of several psychiatric disorders, including substance use disorder (SUD, Gisquet-Verrier and Le Dorze 2019) and posttraumatic stress disorder (PTSD, Bowers and Ressler 2015). While much of the current literature has focused on mechanisms supporting recent memory acquisition and consolidation (Asok et al. 2019), a greater understanding of the neurobiological mechanisms governing persistent, enhanced remote memory, whether shared with recent memory or distinct, could provide new insight into the treatment of memory-related disorders. Additionally, memories that drive unwanted flashbacks of trauma in PTSD are unique from normal episodic memories in that they are intrusive and more life-like in nature (Brewin 2015). Stress, even one acute episode, can impose lasting changes on the brain (McEwen 2007; Zannas and West 2014; Sillivan et al. 2019b), but how stress-induced changes influence or interact with remote memory mechanisms is not wellcharacterized. Here, we used an auditory fear conditioning (FC) paradigm to investigate the role of microRNAs (miRNAs) in the persistence of a remote fear memory. Subsequently, we examined the functional contribution of miRNAs as candidate remote memory regulators in animals with a history of stress that display a wellcharacterized, enhanced remote memory phenotype (Sillivan et al. 2017). Elucidation of remote memory mechanisms in both pathogenic and nonpathogenic states are expected to provide insight into the neurobiology of disorders perpetuated by extinctionresistant, maladaptive memory.

${ }^{3}$ These authors contributed equally to this work. Corresponding author: cmiller@scripps.edu

Article is online at http://www.learnmem.org/cgi/doi/10.1101/lm.048827.118.
miRNAs are small, approximately 22-24 nt long, noncoding RNAs that repress translation of target mRNAs (Filipowicz et al. 2008; Gebert and MacRae 2019). miRNAs interact with multiple functional targets directly at the $3^{\prime}$ untranslated region of the target mRNA based on complimentary sequences and, therefore, have been hypothesized to support the complex patterns of gene regulation required to support not only the initial formation of longterm memory, but also the persistence of remote memory (Sillivan et al. 2019a). In an early example linking miRNAs to learning and memory, knockdown of Dicer1, an enzyme required for mature miRNA processing, enhanced memory performance in the Morris Water Maze, trace FC, and contextual FC (Konopka et al. 2010), confirming that miRNA function influences recent memory performance in several different types of tasks. More specifically, Gao et al. (2010) demonstrated that hippocampal miR-134 overexpression impairs memory acquisition by targeting both cAMP response binding element protein (CREB) and brainderived neurotrophic factor (BDNF) in a contextual FC task. We have previously shown that auditory FC down-regulates miR-182 in the lateral amygdala and that overexpression of miR-182 in this region during training disrupted expression of the fear memory the following day (Griggs et al. 2013). While these reports and others provide evidence that miRNAs can support recent memory (Lin et al. 2011; Dias et al. 2014; Volk et al. 2014), studies to date have not addressed their role in remote memory. We hypothesized

(C) 2019 Jones et al. This article is distributed exclusively by Cold Spring Harbor Laboratory Press for the first 12 months after the full-issue publication date (see http://learnmem.cshlp.org/site/misc/terms.xhtml). After 12 months, it is available under a Creative Commons License (Attribution-NonCommercial 4.0 International), as described at http://creativecommons.org/licenses/by-nc/4.0/. 
that formation of a remote memory induces changes in the basolateral amygdala (BLA) miRNA profile that functions to support long-term remote memory. We focused our analyses on the BLA because of the known contribution of this region to fear learning and memory storage at remote time points (Gale et al. 2004; Rodrigues et al. 2004; Mantzur et al. 2009; Zelikowsky et al. 2014). Additionally, we hypothesized that miRNA pathways may be dysregulated by stress, contributing to a stress-induced enhancement of fear memory and its delayed extinction (Sillivan et al. 2017). Consistent with this hypothesis, we recently demonstrated that exposure to a single acute stressor (120 min of restraint stress) induces a change in the molecular profile of the BLA, including differential expression of miRNAs an entire month after stress (Sillivan et al. 2019b). Differential miRNA expression has also been reported in the serum of patients with PTSD (Zhou et al. 2014; Martin et al. 2017; Sillivan et al. 2019a) and between rats selectively bred for high or low stress reactivity (Cohen et al. 2017). The behavioral consequences of stress exposure have also been linked to miRNA function in the amygdala in several reports. For example, Haramati et al. (2011) identified several miRNAs regulated by acute stress and showed that central amygdala (CeA) overexpression of mir-34c protected against stress-induced increases in anxiety-like behavior in the light-dark transfer test. Similarly, transgenic overexpression of mir-26a-2 protected against increases in anxiety-like behavior induced by social defeat stress (Xie et al. 2019). Thus, miRNAs regulate both stress-induced behaviors and learning and memory, suggesting they may make an important contribution to PTSD susceptibility (Sillivan et al. 2017). For that reason, a second goal of the experiments reported herein was to examine miRNA involvement in susceptibility and resilience to stress-enhanced fear memory (SEFM), a PTSD-like phenotype (Sillivan et al. 2017).

\section{Results}

\section{Role of amygdala mir-598-3p in remote fear memory}

We used small-RNA sequencing (smRNA-seq) to identify miRNAs in the BLA that may contribute to the support of a remote fear memory. To isolate memory-associated miRNAs, male mice that underwent auditory FC were compared to naïve mice and those exposed to an unpaired (UNP) protocol. The UNP protocol consisted of the same number of tone and shock presentations, but the tone did not coterminate with the footshock. Further, to isolate the auditory tone as the conditioned stimulus (CS+), a classic protocol was used that involved extensive habituation to the context on the day prior to conditioning. Tissue from the BLA was collected $30 \mathrm{~d}$ after training and small-RNA libraries were prepared and sequenced from biological replicate samples. This was performed at two independent sequencing facilities on two independent animal cohorts and the data from each was compared to identify miRNAs differentially regulated in both runs (Fig. 1A). To confirm that FC, but not the UNP protocol, resulted in cue-specific learning, a separate cohort of mice underwent a retrieval session in a distinct context $30 \mathrm{~d}$ after training. As expected, FC but not UNP mice displayed remote fear memory expression in response to tone presentations (Fig. 1B; RM ANOVA, main effect of group: $F_{(1,65)}=$ 9.991, $P=0.002$ ).

miRNAs that were identified as differentially expressed in both smRNA-seq runs by at least $0.5 \log _{2}$ fold change between FC mice and both UNP and naïve are displayed in Figure 1C (and Supplemental File 1). Nine miRNAs were differentially expressed, all of which were down-regulated in the FC condition. mir-598$3 p$ was selected for further analysis based on its novelty, as its function had not yet been explored in the brain. The learning-induced decrease in mir-598-3p was validated by quantitative polymerase chain reaction (qPCR) (Naïve: mean $=1.0 \pm 0.15$; FC: mean $=0.66$ \pm 0.08 ; one-tailed $t$-test: $t_{(17)}=2.181, P=0.022$ ) and its expression pattern in the BLA was examined by fluorescent in situ hybridization (Fig. 1D). Further, we characterized its relative values in the BLA, cerebellum (CER), prefrontal cortex (PFC), hypothalamus (HYP), thalamus (THA), and hippocampus (HPC) of naïve mice (Fig. 1E), finding the highest expression in CER and lowest in HYP. Cellular localization analysis revealed that mir-598-3p is expressed throughout cells, including in the synaptoneurosome fraction, in the BLA, cortex, and striatum (Fig. 1F). Interestingly, the ratio of mir-598-3p expression in the synaptoneurosome relative to the rest of the cell was highest in the BLA.

We next determined the potential for in vivo inhibition of mir-598-3p within the BLA to enhance remote fear memory expression. Mice underwent cued FC and received either a synthetic hairpin miRNA inhibitor targeting mir-598-3p (mir-598-3p-INH) or a control inhibitor 28 d later (Fig. 1G,H; mir-598-3p levels in mir-598-3p-INH vs. control two tailed $t$-test: $t_{(10)}=3.12$, $P=0.011$ ). Remote fear memory was assessed based on freezing during the first set of tone presentations (Bin 1) in a distinct context, followed by assessment of extinction in the same session with the presentation of an additional 24 tones. All mice exhibited little to no pretone freezing (INH: mean $=4.66 \pm 1.51$, CTL: mean $=6.96 \pm 1.95$ ). Critically, there was no effect of treatment on retrieval, as freezing was equivalent during Bin 1 tone presentations (Fig. 1I; two-tailed independent samples $t$-test: $t_{(25)}=$ 0.240, $P=0.812$ ). BLA mir-598-3p inhibition also did not alter remote fear memory extinction (Fig. 1I). We observed a significant effect of time $\left(F_{(4,125)}=27.642, P<0.001\right)$, indicating that freezing behavior diminished across the extinction session, but no effect of mir-598-3p-INH treatment $\left(F_{(1,125)}=0.024, P=0.878\right)$. There was also no effect of treatment on the rate of extinction across the session (two-tailed independent samples $t$-test: $t_{(25)}=$ $0.701, P=0.490)$.

\section{Amygdala mir-598-3p is differentially expressed in stress susceptible and resilient mice and regulates stress-enhanced fear memory (SEFM)}

We previously developed a protocol through which stress prior to FC results in an enhancement of fear memory in a subgroup of mice (Sillivan et al. 2017). Specifically, male mice display differential susceptibility to the effects of stress and the susceptible (SS) and resilient (SR) animals can be identified by their freezing behavior during the final minute of FC, without additional phenotyping and prior to remote memory recall. Expression of the remote SEFM is accompanied by immediate early gene activation in the BLA and changes to BLA mRNA expression of genes reported to be altered in subjects diagnosed with PTSD, including adenylate cyclase activating polypeptide 1 (PACAP), BDNF, and tyrosine hydroxylase. In contrast to males, female mice display a consistent susceptible-like phenotype following SEFL, exhibiting SEFM comparable to that of SS males (Sillivan et al. 2017).

Given the behavioral interaction between stress and FC and the involvement of the BLA, we decided to next assess the longterm impact of restraint stress alone or SEFL training on BLA mir-598-3p levels. Tissue was collected for qPCR analysis of mir-598-3p $30 \mathrm{~d}$ after stress, FC, or SEFL and freezing behavior was analyzed during the last minute of training in SEFL males to identify SS and SR subgroups (Fig. 2A; Sillivan et al. 2017). In males, mir-598-3p was differentially expressed across the five groups tested one month after behavioral manipulation (Fig. 2B, left panel; oneway ANOVA: $\left.F_{(4,36)}=9.447, P<0.001\right)$. Fisher's least significant difference (LSD) post hoc comparisons indicated that stress increased mir-598-3p $(P=0.004)$, while FC decreased the miRNA, $(P=0.043)$, relative to naïve mice. Among mice that underwent SEFL, SS mice exhibited significantly higher mir-598-3p than SR mice $(P=$ 

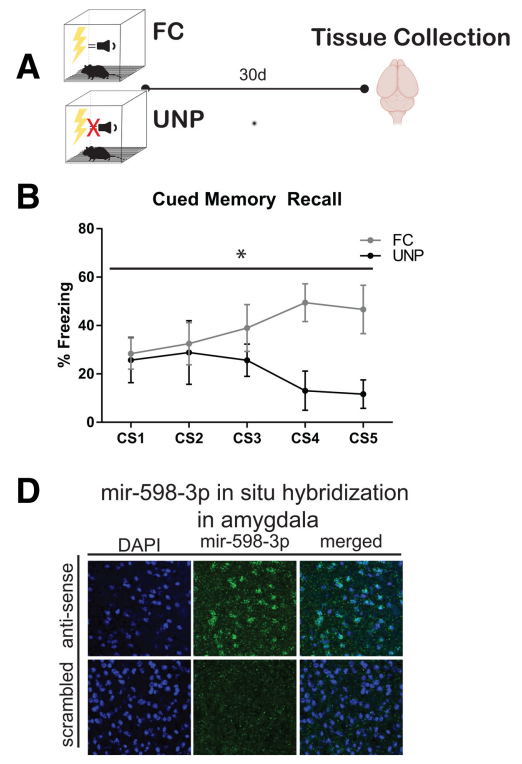

G

H

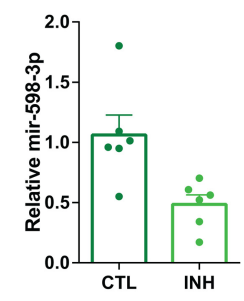

C

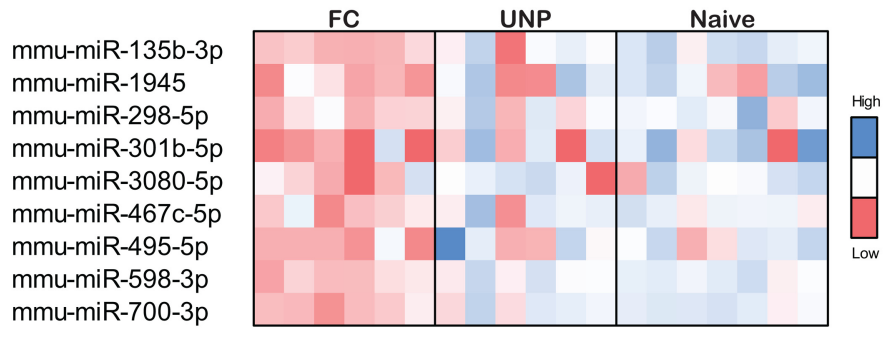

E

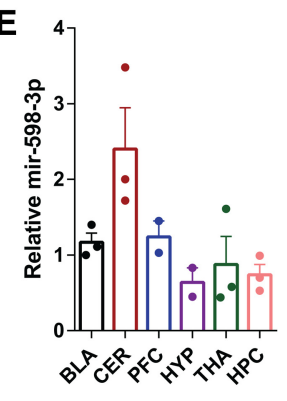

F
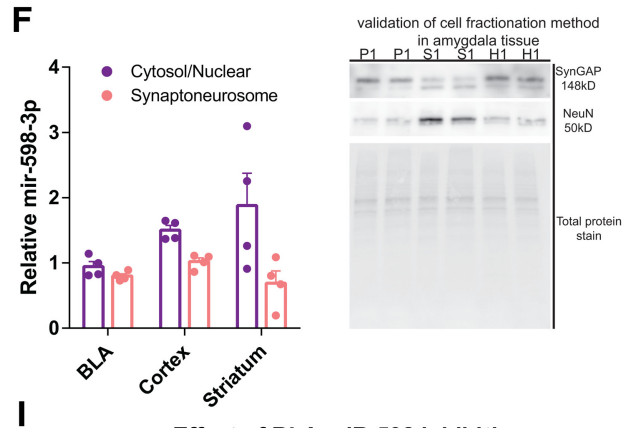

Effect of BLA miR-598 inhibition on remote fear memory
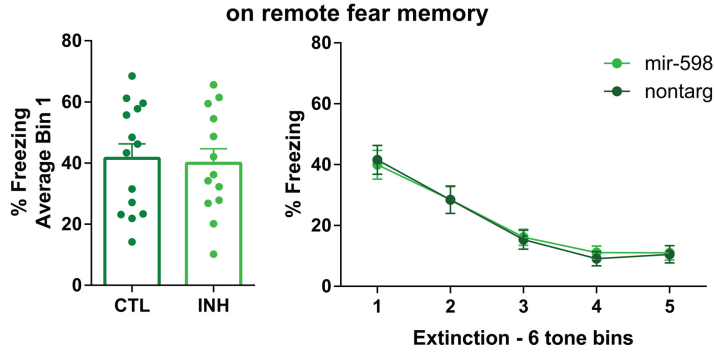

Figure 1. Role of mir-598-3p in remote fear memory expression. (A) Schematic of experimental design for smRNA-seq experiments, conducted in male mice. (B) Training resulted in cue-specific memory expression in FC mice, but not UNP mice, * main effect of group, $P<0.05$. (C) miRNAs identified as differentially expressed by $0.5 \log _{2}$ fold change between both FC and UNP and FC and naïve comparisons. (D) BLA expression of mir-598-3p by fluorescent in situ hybridization. (E) mir-598-3p relative expression in BLA, cerebellum (CER), prefrontal cortex (PFC), hypothalamus (HYP), thalamus (THA), and hippocampus (HPC). Values are relative to the average ddCt value of all regions. $(F)$ Cell fractionation protocol used to measure relative mir-598-3p in the synaptoneurosome and cytosol in the BLA, cortex and striatum (STR). Western blotting confirmed the pellet (P) expressed a known synaptic marker (SynGAP) while the supernatant $(\mathrm{S})$ expressed a known nuclear marker (NeuN), validating the cell fractionation method to isolate the synaptoneurosome and cytosol. (G) Mir-598-3p levels after intra-BLA inhibition. $\left(^{*}\right) P<0.05(H)$ Schematic shows mir-598-3p inhibition in the BLA $28 \mathrm{~d}$ after cued FC, followed by a test of remote fear memory expression during an extinction session in a unique context. $(I)$ mir-598-3p expression did not alter fear memory recall or extinction (left and right panels). FC $n=13-14$ per group. Data presented are \% freezing normalized to individual pretone freezing in six tone bins and as average freezing during the first six tone bin (memory recall).

0.044). Interestingly, female mice exhibited no change in mir-598-3p after stress, FC, or SEFL (Fig. 2B, right panel; one-way ANOVA: $\left.F_{(3,22)}=0.123, P=0.945\right)$.

To determine the time course leading up to the mir-598-3p expression differences observed in males $30 \mathrm{~d}$ after training, we ran additional cohorts, collecting tissue $24 \mathrm{~h}$ or $7 \mathrm{~d}$ later (Fig. 2A). The results indicate a surprisingly dynamic level of regulation of mir-598-3p in the BLA over time. At $24 \mathrm{~h}$, mir-598-3p was differentially expressed (Fig. 2C, left panel; one-way ANOVA: $F_{(4,34)}=$ $3.016, P=0.031)$. LSD post hoc comparisons revealed that mir-598-3p was significantly increased in SEFL mice, relative to naïve and stress alone, and that the difference was significant for both SS (naïve $P=0.009$, stress $P=0.049$ ) and SR subgroups (naïve $P=0.036$, stress $P=0.012$ ). At $7 \mathrm{~d}$, there were no significant group differences in mir-598-3p expression (Fig. 2C, right panel; one-way ANOVA: $\left.F_{(4,33)}=2.371, P=0.072\right)$, yet this continued to change, as evidenced by the $30 \mathrm{~d}$ data (Fig. $2 \mathrm{~B}$ ). These results demonstrate that SEFL induces an initial increase in BLA mir-598-3p that persists over time in SS mice, while SR levels drop to FC only control levels by $30 \mathrm{~d}$. One interpretation is that the stress-induced increase in mir-598-3p dominates the response to SEFL in SS mice, while the FC-induced decrease in mir-598-3p dominates the response to SEFL in SR mice over time. Subsequently, we hypothesized that inhibition of mir-598-3p in SS mice would protect against the development of SEFM, mimicking an SR-like memory phenotype.

To determine the regional specificity of the elevated mir-598-3p in SS males, mir-598-3p was also measured in the PFC, dorsal hippocampus (HPC) bed nucleus of the stria terminalis (BNST), and cerebellum (CER) $30 \mathrm{~d}$ after training (Fig. 1D). Differential expression across the five behavioral groups was not detected in the PFC (one-way ANOVA: $F_{(4,33)}=1.917, P=0.131$ ), HPC (one-way ANOVA: $F_{(4,34)}=1.559, P=0.208$, or BNST (one-way ANOVA: $F_{(4,33)}=1.718, P=0.173$. While mir-598-3p was differentially expressed in the cerebellum (one-way ANOVA: $F_{(4,34)}=$ $3.356, P=0.02)$ in that stress $(P=0.029)$ and FC $(P=0.003)$ mice exhibited higher mir-598-3p than naïve mice, there was no difference 
A

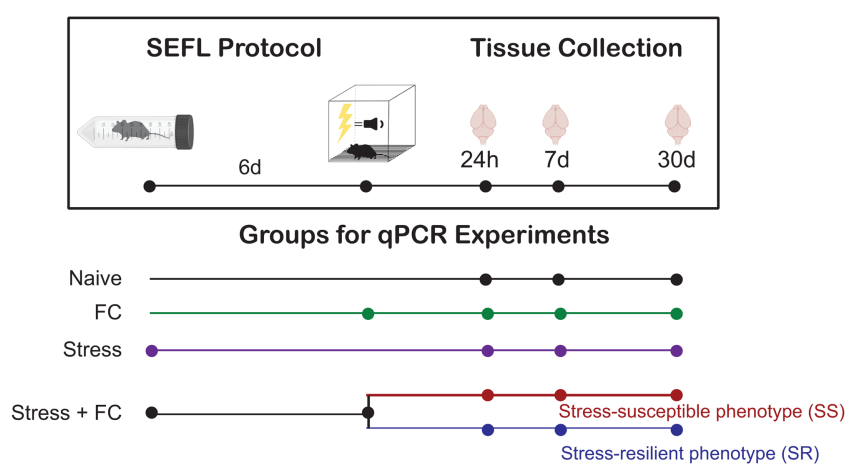

\section{B}

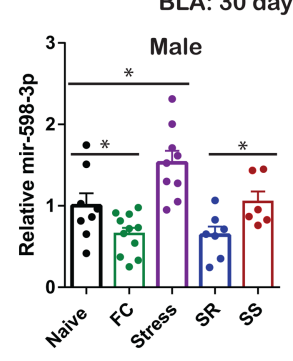

C
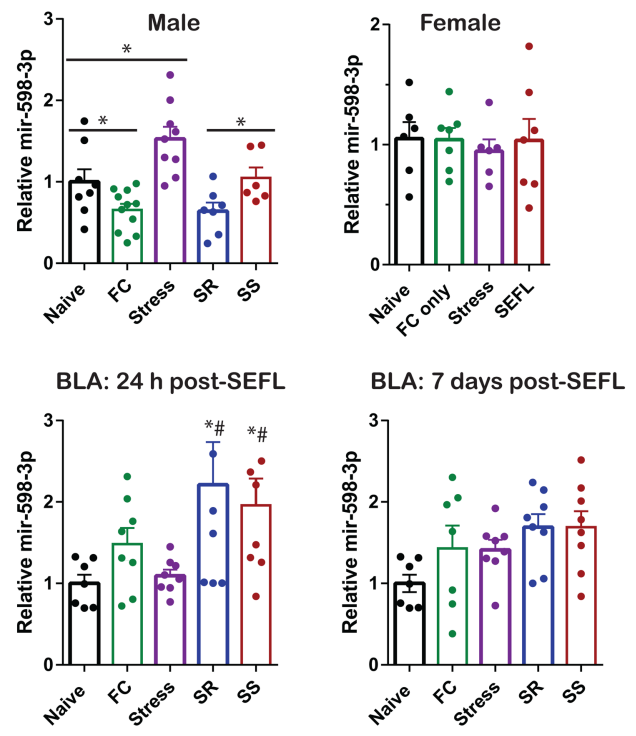
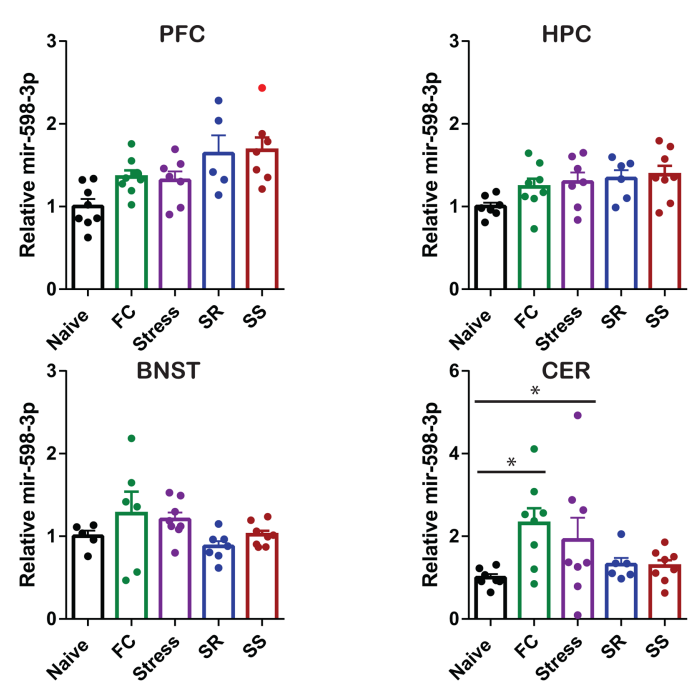

E

BLA mir-598-3p-INH

$\mathbf{F}$

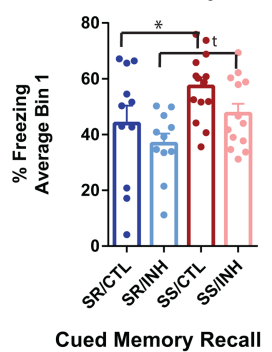

Effect of BLA miR-598 inhibition on SEFM in males

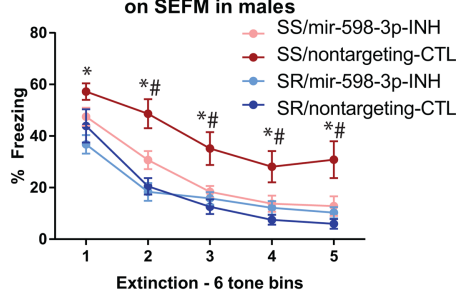

G

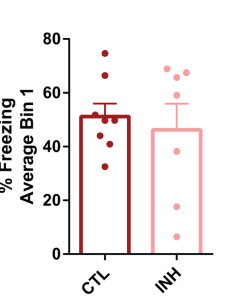

Effect of BLA miR-598 inhibition on SEFM in females

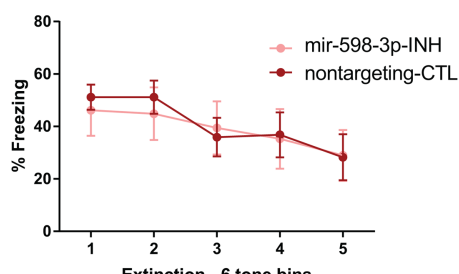

Figure 2. Amygdala mir-598-3p is differentially expressed in stress susceptible and resilient mice and regulates stress-enhanced fear memory (SEFM) in susceptible mice. (A) Schematic of experimental design. (B) Relative mir-598-3p expression in males and females $30 \mathrm{~d}$ after FC, Stress, or SEFL. Male $n=7-11$ per group, Female $n=6-7$ per group; $\left(^{*}\right) P<0.05$. (C) Relative mir-598-3p expression in males $24 \mathrm{~h}$ and $7 \mathrm{~d}$ after FC, Stress, or SEFL. Twenty-four hours $n=6-8,7 \mathrm{~d} n=7-8$ per group; $\left(^{*}\right) P<0.05$ vs. naïe, (\#) $P<0.05$ vs. stress. $(D)$ Relative mir-598-3p expression in the PFC, HPC, BNST, and CER $30 \mathrm{~d}$ post-SEFL in male mice, $n=5-8$ per group, $\left({ }^{*}\right) P<0.05$. (E) Schematic of mir-598-3p inhibition experimental design. $(F)$ BLA mir-598-3p inhibition attenuated stress-enhanced fear memory (SEFM) in male SS mice. SR $n=11$ per group, SS $n=13-14$ per group; * SR/CTL vs. SS/ CTL $P<0.05$; \# SS/CTL vs. SS/INH $P<0.05 ; t P=0.052$. (G) BLA mir-598-3p inhibition did not alter SEFM in female mice. Female $n=7-8$ per group. Behavioral data are presented as \% freezing normalized to individual pretone freezing in six tone bins and as average freezing during the first six tone bin (memory recall).

between SR and SS mice $(P=0.744)$. This highlighted the unique nature of the mir-598-3p elevation of in the BLA of SS mice.

We next determined the effect of inhibiting mir-598-3p on remote SEFM in the BLA one month after SEFL training. Twenty-eight days after SEFL training, male and female mice received bilateral intra-BLA infusions of mir-598-3p-INH or a nontargeting control, and remote fear memory was assessed $2 \mathrm{~d}$ later (Fig. 2E). We observed little to no pretone freezing in all treatment groups (SR/CTL mean $=6.33 \pm 1.497, \quad S R / I N H$ mean $=3.971 \pm$ $1.067, \mathrm{SS} / \mathrm{CTL}$ mean $=5.779 \pm 1.610, \mathrm{SS} / \mathrm{INH}$ mean $=11.49 \pm$ 2.781). SS males froze more than SR males during the first bin of tone presentations $\left(F_{(1,45)}=8.061, P=0.007\right)$ and there was a strong trend toward a main effect of treatment $\left(F_{(1,45)}=4.0, P=0.052\right)$, indicating an attenuation of remote fear memory recall with mir-598-3p inhibition. Further, freezing behavior diminished across the entire session (Fig. $2 \mathrm{~F} ; \mathrm{F}_{(4,225)}=36.515, P<0.001$ ) and SS mice exhibited the expected SEFM, in that they displayed higher freezing than SR controls (main effect of population: $F_{(1,225)}=$ $51.349, P<0.001)$. Consistent with our hypothesis, BLA inhibition of mir-598-3p attenuated SEFM in SS, but not SR, males (three-way RM ANOVA treatment by population interaction effect: $F_{(1,225)}=$ $16.879, P<0.001$; LSD post hoc comparisons, SS/INH vs. SS/CTL, $P<0.05$ for all comparisons, SR/INH vs. SR/CTL, $P>0.05$ for all comparisons), indicating that mir-598-3p inhibition interferes 
with remote memory, but only when mice display stress-induced enhancement. Importantly, this interaction is not due to a floor effect, as mir-598-3p inhibition attenuated SEFM in SS, but not SR, even at Bins 2 and 3, before SR mice had extinguished and when normalized freezing is still $\sim 20 \%$. Consistent with this, mir-598-3p inhibition increased the rate of extinction learning in SS mice only (two-way ANOVA, treatment by population interaction effect: $F_{(1,44)}=4.767, P=0.034$; LSD post hoc comparisons SS/CTL vs. SS/INH, $P=0.021$; SR/CTL vs. SR/INH, $P=0.424$ ).

In female mice, we observed little to no pretone freezing $(\mathrm{CTL}$ mean $=4.178 \pm 1.216$, INH mean $=4.314 \pm 1.278)$ and BLA mir-598-3p inhibition had no effect on SEFM (Fig. 2G; twoway RM ANOVA, no main effect of treatment: $F_{(1,65)}=0.098$, $P=0.755)$, consistent with the lack of a SEFL-induced increase in mir-598-3p levels (Fig. 2B). In addition, freezing behavior did not decrease across the extinction session (no main effect of CS:, $\left.F_{(4,65)}=1.91, P=0.119\right)$, consistent with our previous report of a uniform memory enhancement displayed by females in response to stress (Sillivan et al. 2017).

\section{Amygdala mir-598-3p does not alter stress-induced} changes in anxiety-like behavior in SEFL or FC mice

A potential interpretation of the reduced SEFM by intra-BLA mir-598-3p inhibition (Fig. 2E) is that it produced an anxiolyticlike effect. This is plausible, given that BLA mir-598-3p is increased following both SEFL and restraint stress alone. Therefore, we next tested the effect of in vivo manipulation of mir-598-3p on anxietylike behaviors observed in male mice exposed to SEFL or FC alone. Twenty-eight days after SEFL or FC, mice received intra-BLA infusions of mir-598-3p-INH or a nontargeting control. Anxiety-like behavior was then measured in the open field test (OFT), elevated plus maze (EPM) and acoustic startle response test (ASR) over three consecutive days (Fig. 3A). In FC only mice, mir-598-3p inhibition appeared to produce an anxiolytic-like phenotype in the OFT (Fig. $\left.3 \mathrm{~B} ; t_{(21)}=2.305, P=0.032\right)$ without altering total distance traveled (Fig. 3C; $t_{(21)}=1.361, P=0.188$ ). However, mir-598-3p inhibition did not alter time in the open vs. closed arm of the EPM (Fig. 3D; $\left.t_{(20)}=0.571, P=0.574\right)$, nor was there a change in total distance traveled in the maze (Fig. $3 \mathrm{E} ; t_{(20)}=1.020, P=0.312$ ). There was no effect of mir-598-3p inhibition on acoustic startle in FC only mice (Fig. $3 \mathrm{~F} ; t_{(22)}=1.736, P=0.097$ ).

Thirty days after SEFL training, we observed a significant population by mir-598-3p treatment interaction on anxiety-like behavior in the OFT (Fig. 3G; $F_{(1,34)}=12.657, P=0.001$ ). Post hoc analyses confirmed an anxiogenic-like phenotype in SS mice $30 \mathrm{~d}$ post-SEFL, as compared to SR controls (SS/CTL vs. SR/CTL, $P=0.002$ ), that was not rescued by mir-598-3p treatment (SS/CTL vs. SS/INH, $P=0.194)$. In addition, mir-598-3p inhibition was anxiogenic-like in SR mice (SR/CTL vs. SR/INH, $P=0.001$ ), in which inhibition has no effect on SEFM. There was also a significant interaction effect in the total distance traveled in the OFT

A

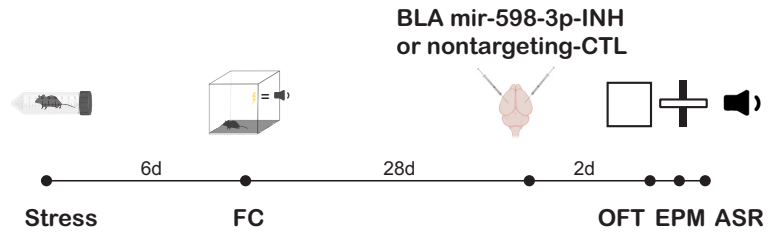

Open Field Test

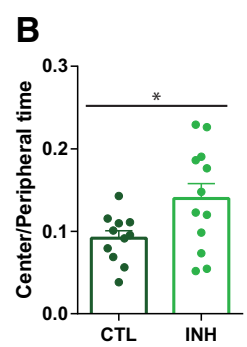

G

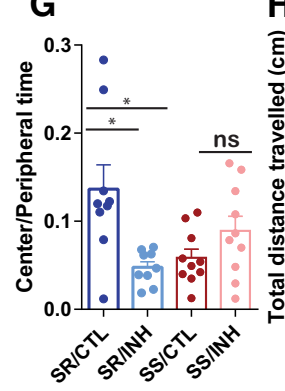

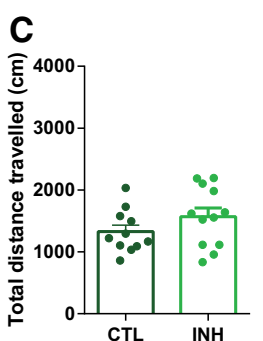

H

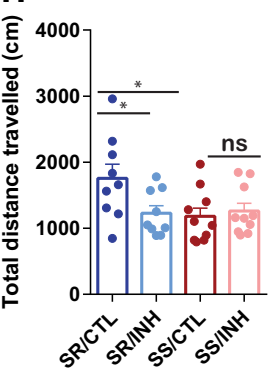

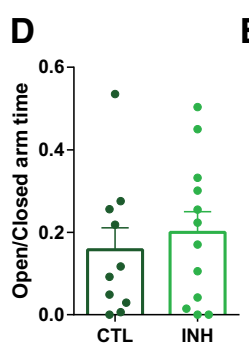

I

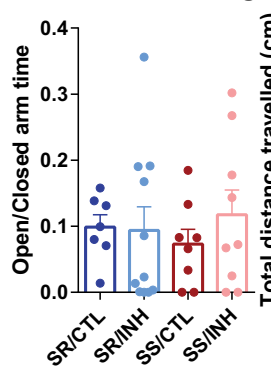

E

$\mathbf{J}$
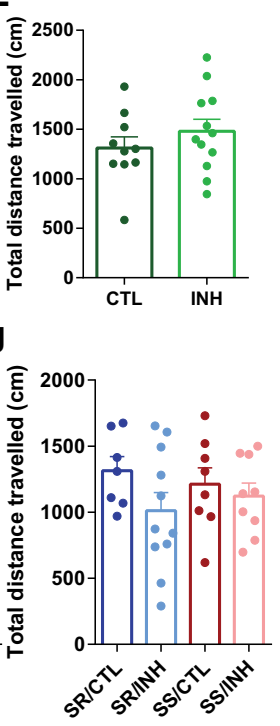

Acoustic Startle Response
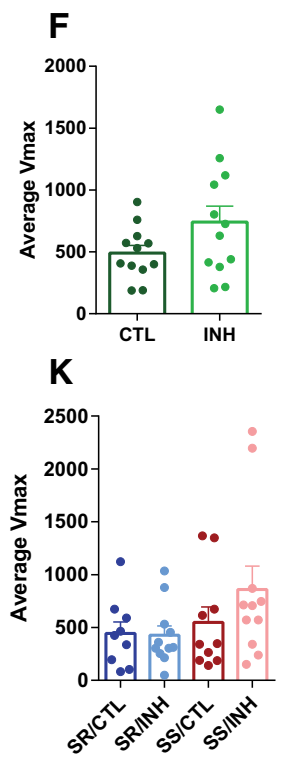

Figure 3. Amygdala mir-598-3p inhibition does not alter anxiety-like behavior in SEFL mice. (A) Schematic of experimental design. Center/Peripheral time $(B)$ and total distance traveled $(C)$ in the open field test (OFT) are presented in FC only mice. Open/Closed time $(D)$ and total distance traveled $(E)$ in the EPM are presented in FC only mice. Average Vmax during the first five tones of the ASR test $(F)$ are presented in FC only mice. Center/ Peripheral time $(G)$ and total distance traveled $(H)$ in the OFT are presented in SEFL mice. Open/Close time $(I)$ and total distance traveled $(J)$ in the EPM are presented in SEFL mice. Average Vmax during the first five tones of the ASR test $(K)$ are presented in SEFL mice. $\left(^{*}\right) P<0.05$; ns $=$ not significantly different; FC $n=10-12$ per group; SR $n=7-11$ per group, SS $n=8-10$ per group. 
A

\section{D}

Differentially expressed predicted mir-598-3p targets
Tissue Collection

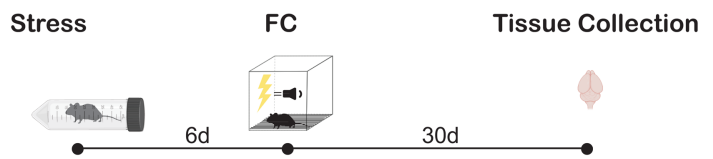

$23 \%$ of predicted targets detected in the BLA $(62 / 272)$

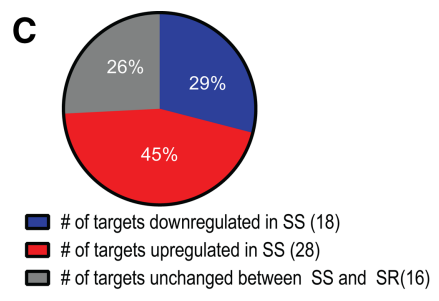

Selected functional annotations of downregulated predicted mir-598-3p targets

\begin{tabular}{|l|r|}
\hline \multicolumn{2}{|l|}{$\log _{2}$ FC } \\
Gene ID & SS/SR \\
\hline Gnaq & 2.52 \\
\hline Tmem30a & 2.41 \\
\hline Cluh & 2.34 \\
\hline Bcr & 1.73 \\
\hline Nsf & 1.49 \\
\hline Gna13 & 1.46 \\
\hline Abcd3 & 1.40 \\
\hline Ankrd44 & 1.35 \\
\hline Kif1a & 1.34 \\
\hline Osbpl8 & 1.28 \\
\hline
\end{tabular}

E

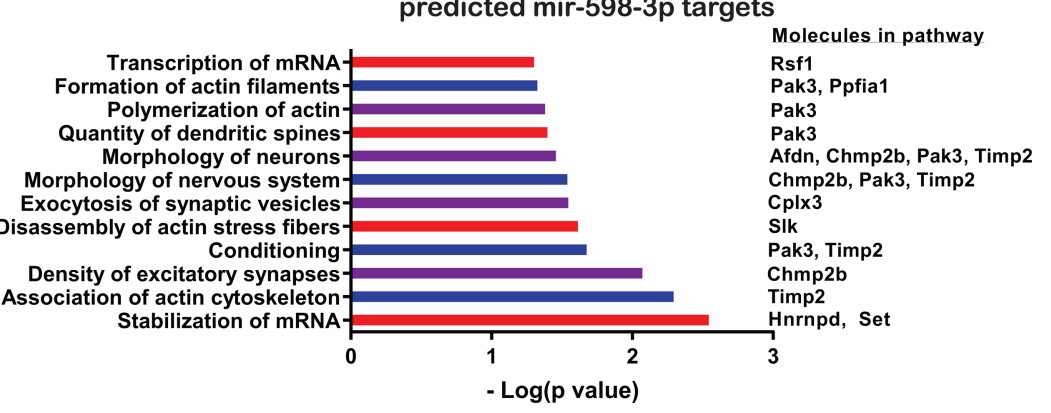

Figure 4. Putative mir-598-3p targets are differentially expressed in the BLA of stress susceptible and resilient mice. (A) Schematic of experimental design. $(B)$ Two hundred and seventy-two protein targets were predicted by at least two of the three databases, $23 \%$ of those were detected at the level of the proteome in the BLA. (C) $29 \%$ of predicted targets were down-regulated in SS mice, $45 \%$ of predicted targets were up-regulated in SS mice, and $26 \%$ of

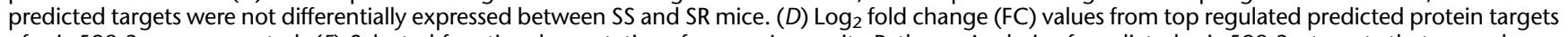
of mir-598-3p are presented. (E) Selected functional annotations from an Ingenuity Pathway Analysis of predicted mir-598-3p targets that were downregulated in SS mice compared to SR and the molecules associated with each.

(Fig. $3 \mathrm{H} ; F_{(1,34)}=4.407, P=0.043$; SS/CTL vs. SR/CTL, $P=0.008$; SS/CTL vs. SS/INH, $P=0.684 ;$ SR/CTL vs. SR/INH, $P=0.017)$. Importantly, mir-598-3p inhibition did not affect anxiety-like behavior or distance traveled in the OFT in SS Mice. This was unexpected in that SS inhibitor mice display reduced fear memory on par with SR controls, but these data suggest that mir-598-3p inhibition does not similarly protect against any stress-induced increases in anxiety-like behavior in the open field. Taken together, these results suggest a decoupling of stress from anxiety-like behaviors. mir-598-3p inhibition produced no change in anxiety-like behavior in the EPM (Fig. 3I; $F_{(1,31)}=0.362, P=0.552$ ) and there was no effect of population between SS and SR control mice (Fig. 3I; $\left.F_{(1,31)}=0.002, P=0.969\right)$. There was also no effect of mir-598-3pINH (Fig. 3J; $F_{(1,31)}=2.464, P=0.127$ ) or of population (Fig. 3J, $\left.F_{(1,31)}=0.001, P=0.970\right)$ on the total distance traveled in the maze. Similarly, there was no effect of mir-598-3p (Fig. 3K; $F_{(1,37)}$ $=0.913, P=0.346$ ) or population (Fig. $3 \mathrm{~K} ; F_{(1,37)}=3.006, P=$ 0.091) on ASR in SR or SS mice. Collectively, these data suggest that an anxiogenic-like phenotype in the open field test develops in SS mice over time, as thigmotaxis is increased and general locomotor exploration decreased in control animals $30 \mathrm{~d}$ post-SEFL, but not at the earlier time point of $4 \mathrm{~d}$ post-SEFL we previously assessed (Sillivan et al. 2017). Importantly, mir-598-3p is not functionally related to this effect or to anxiety-like behavior in the EPM or ASR.

\section{Putative mir-598-3p targets are differentially expressed in the BLA of stress susceptible and resilient mice} miRNAs have the potential to titrate expression levels of multiple protein targets, creating complex miRNA-mRNA interaction patterns that may underlie functional consequences of the in vivo manipulations of mir-598-3p described here. We examined the BLA proteome in SS and SR mice $30 \mathrm{~d}$ after SEFL training (Fig. 4A; Sillivan et al. 2019a) and used three miRNA databases that organize known miRNA sequences and predict protein targets based on seed sequences to identify potential functional targets of mir-598-3p
(DIANA (Karagkouni et al. 2018), TargetScan (Agarwal et al. 2015), and miRbase (Kozomara et al. 2019)). Proteins predicted by at least two of three databases were considered to be potential targets of mir-598-3p. Twenty-three percent of predicted mir-598-3p targets were detected in the amygdala at the level of the proteome (Fig. 4B). Proteins that differed by at least $0.5 \log _{2}$ fold change were considered to be differentially expressed between SS and SR mice and of these, $29 \%$ were down-regulated in SS mice, $45 \%$ were up-regulated in SS mice, and $26 \%$ were not differentially expressed (Fig. 4C). The 10 proteins that are predicted targets of mir-598-3p and are differentially expressed in SS compared to SR mice to the greatest degree, both up and down, are presented in Figure 4D. Because mir-598-3p is up-regulated in SS mice, proteins functionally related to the protective effect of mir-598-3p inhibition on SEFL would be expected to be down-regulated in SS mice. To explore potential functional annotations related to our observed effect, we conducted an Ingenuity Pathway Analysis on these down-regulated putative mir-598-3p targets and identified several functional pathways that are involved in synaptic transmission and synaptic plasticity, including "density of excitatory synapses" and "quantity of dendritic spines." Interestingly, several pathways point specifically to the regulation of the actin cytoskeleton, a crucial component of structural plasticity supporting functional plasticity (Hotulainen and Hoogenraad 2010; Kasai et al. 2010; Novaes et al. 2018). Selected functional annotations and the protein targets associated with each are presented in Figure 4E. This includes representation of Pak3 in several functional annotations, which interacts directly with Rho GTPases to regulate the actin cytoskeleton (Ramakers 2002).

\section{Discussion}

The smRNA-seq results presented here identify nine BLA miRNAs down-regulated one month after cued FC, suggesting they may contribute to the persistence of remote memory. Interestingly, when assessing remote time points ( 1 mo posttraining), we found 
that mir-598-3p is down-regulated in the BLA following cued FC, but up-regulated after exposure to acute stress. While it does not preclude the possibility that overexpressing mir-598-3p in the BLA would disrupt a remote fear memory, we found that further reduction of its levels in the BLA did not produce memory enhancement. Subsequently, we used our SEFL protocol (Sillivan et al. 2017), in which mice are exposed to an acute stressor followed by cued FC 1 wk later, to examine the role of mir-598-3p in susceptibility and/or resilience to the development of a remote SEFM. Thirty days after SEFL, amygdala mir-598-3p was increased in SS compared to SR mice and in vivo inhibition of mir-598-3p attenuated SEFM in SS mice, mimicking the SR phenotype. Further, we observed an anxiety-like phenotype in SS mice $30 \mathrm{~d}$ after SEFL relative to SR mice that was not altered by the same manipulation of mir-598-3p. Thus, the effect of BLA mir-598-3p inhibition was specific to memory, failing to influence general anxiety-like behaviors. Consistent with a memory-specific role for mir-598-3p, pathway analysis of putative targets of mir-598-3p that were found to be down-regulated in SS mice compared to SR in our quantitative proteomics data set revealed several functional pathways related to plasticity underlying learning and memory.

In the first description of a behavioral effect linked to mir-598-3p in the brain, we show SS mice fail to exhibit the timedependent reduction in BLA mir-598-3p levels that FC and SR groups exhibited $30 \mathrm{~d}$ after learning. BLA mir-598-3p inhibition in SS mice protected against SEFM and restored extinction learning to SR and FC levels, without a comparable anxiolytic effect. The memory-, SS- and sex-specific effect of mir-598-3p manipulation suggests that the functional pathways targeted are specifically related to the impact of stress on memory. Interestingly, a precursor miRNA family, mir-19b, has been implicated in PTSD (Zhou et al. 2014; Martin et al. 2017) and is differentially expressed between SS and SR mice in our own laboratory(Sillivan et al. 2019a). This same miRNA is enhanced in the amygdala following chronic social defeat stress and mir-19b in vivo manipulation bidirectionally modulated cued FC without altering contextual fear memory or anxiety-like behavior in the OFT, dark/light transfer test, or the EPM (Volk et al. 2014). Further study of miRNAs altered by stress, such as mir-19b or mir-598-3p, which specifically influence amygdala-dependent memory without altering general anxietylike behavior, may provide further insight into mechanisms contributing to PTSD.

The pathway analysis conducted on putative targets of mir-598-3p detected to be down-regulated in SS mice revealed several pathways linked to learning and plasticity. Plasticity of dendritic spines is critical for long-term memory formation (Yang et al. 2009) and is supported by actin polymerization (Smart and Halpain 2000). Several functional annotations we report here that are related to actin dynamics involved two proteins in particular, P21 (Rac1) activated kinase 3 (Pak3) and tissue inhibitor of metalloproteinase 2 (Timp2). Pak3 interacts directly with Rho GTPases to regulate actin dynamics driving rapid cytoskeletal reorganization in the adult brain (Ramakers 2002). It is most commonly associated with intellectual disability (Muthusamy et al. 2017) and inactivation of Pak3 in the forebrain is associated with impaired spatial memory in the Morris Water Maze and contextual FC, while sparing cued FC memory (Hayashi et al. 2004). This is interesting, given that our results suggest lower levels of Pak3 are associated with enhanced memory following a stressor, rather than impaired memory, and suggests that a background of stress might alter endogenous levels of Pak3. Timp2 regulates degradation of the extracellular matrix (Perez-Martinez and Jaworski 2005). While there is little known about the direct role of Timp2 in learning and memory, the extracellular matrix maintains direct contact with synapses and is known to influence dendritic spine stability and synapse structure (Levy et al. 2014). In addition, it is reduced in patients with recurrent depressive symptoms (Bobińska et al. 2016). The potential connection to depressive symptoms is interesting given the down-regulation observed in our PTSD-like phenotype (SS mice) and the high comorbidity between PTSD and major depressive disorder in patients (Jaksic et al. 2017).

While there are no reports of the effect of central mir-598-3p on learning in the literature, mir-598-3p is down-regulated in the cerebrospinal fluid of patients diagnosed with Alzheimer's disease (Riancho et al. 2017). Given that Alzheimer's is associated with significant memory impairment as the disease progresses, this is consistent with up-regulated mir-598-3p in SS mice without retrieval being associated with an enhanced fear memory. While there was no effect of amygdala mir-598-3p inhibition in FC only or SR mice, the effect of mir-598-3p on memory could be targetdependent, in that baseline levels of mir-598-3p and its putative targets could determine which functional targets the miRNA interacts within different contexts. This is consistent with the distinct anxiety-like effects of mir-598-3p inhibition in the OFT that we observed between FC, SR, and SS treatment groups, that did not correspond to levels of mir-598-3p at the time of inhibition.

We observed opposing effects of mir-598-3p inhibition in FC (anxiolytic-like) and SR (anxiogenic-like) mice in the OFT. Interestingly, Dicer1 knockdown (Haramati et al. 2011) and miR-135a inhibition (Issler et al. 2014; Mannironi et al. 2018) in the amygdala were anxiogenic-like in the EPM. In addition, miRNAs have been hypothesized to influence anxiety-like behavior potentially through metabolic or inflammatory mechanisms as several miRNAs, for example mir-34c and mir-26a family miRNAs, are implicated in both changes in inflammation and the modulation of anxiety-like behavior (Haramati et al. 2011; Meydan et al. 2016; Xie et al. 2019). Inflammation is traditionally associated with enhanced anxiety (Michopoulos et al. 2017), and consistently, mir-26a has been shown to be anti-inflammatory and anxiolytic (Zhang et al. 2018; Xie et al. 2019). Future studies could explore the role of other putative targets of mir-598-3p involved in inflammation to better understand its potential role in anxiety in either naïve or stress-resilient mice.

In summary, we identified amygdala mir-598-3p as one miRNA supporting the persistence of memory that is regulated by stress and may underlie remote stress-enhanced fear memory. Our findings suggest the effect of mir-598-3p inhibition is specific to susceptible mice and to memory, as there was no anxiolytic affect in the EPM, OFT, or ASR associated with the effect. Further study of putative targets of mir-598-3p in SS mice could ultimately provide insight for treatments aimed at targeting the selective disruption of traumatic memory.

\section{Materials and Methods}

\section{Animals}

Adult C57BL/6 mice, 8 wk of age (The Jackson Laboratory), were maintained on a 12:12 h light-dark cycle and supplied with food and water ad libitum. Animals were housed 3-4/cage, acclimated to the facility for $1 \mathrm{wk}$ then handled for $3 \mathrm{~d}$ prior to experiments. Behavioral tests were performed during the light cycle. Treatment groups were randomized for all behavioral experiments to prevent batch effects due to time of day. Procedures were performed in accordance with the Institutional Animal Care and Use Committee (IACUC) at the Scripps Florida Research Institute and with national regulations and policies.

\section{Behavioral paradigms}

\section{Cued fear conditioning}

In order to habituate mice to the context, $24 \mathrm{~h}$ prior to cued FC mice underwent a thorough habituation protocol of $3 \times 4 \mathrm{~min}$ 
exposures (12 min total) to the FC chamber. The FC context consisted of grid floors, dim lighting in the room and no light in the chamber, and $70 \%$ ethanol was used to clean between and prior to trials. On the day of cued FC training, mice underwent the following cued FC protocol in this context: 2 min of exploration, 2 CS-US pairings (120 sec intertrial interval) in which an auditory tone $(85 \mathrm{~dB}, 10 \mathrm{kHz})$ coterminated with a $0.5 \mathrm{~mA}(1 \mathrm{sec})$ footshock, and $1 \mathrm{~min}$ of exploration. (Mice in the UNP group were exposed to the chamber for the same amount of time and exposed to two 0.5 $\mathrm{mA}(1 \mathrm{sec})$ footshocks that did not coterminate with the two auditory tones $(85 \mathrm{~dB}, 10 \mathrm{kHz})$.) Fear memory recall was examined $30 \mathrm{~d}$ later in a distinct extinction/recall context. The extinction context consisted of smooth plastic floors and wall inserts, bright light in the room and in the chamber, an orange scent in each chamber, $65 \mathrm{~dB}$ white noise throughout the session, and isopropanol was used to clean between and prior to all trials. For extinction/recall sessions, 5 or 30 tones were presented without footshock with a $60 \mathrm{sec}$ intertrial interval and freezing to the tone was measured. Extinction and recall freezing behavior was normalized to individual pretone freezing to isolate cue-specific freezing (CS freezing $=\%$ freezing during the CS-\% pretone freezing for each individual mouse) and the rate of extinction was calculated as rate of extinction $=$ (average $\%$ freezing during the first three tones) - (average $\%$ freezing during the last three tones)/(average $\%$ freezing during the first three tones) $\times 100$.

\section{Stress-enhanced fear learning}

Stress-enhanced fear learning (SEFL) was performed as previously described (Sillivan et al. 2017, 2019a) The procedure combines a single acute restraint stress session with auditory FC described above to produce stress susceptible (SS) and stress resilient (SR) populations of animals. Briefly, mice were exposed to $2 \mathrm{~h}$ of restraint stress (clear $50 \mathrm{~mL}$ conical tubes) or exposed to a novel holding room for $2 \mathrm{~h}$ during which they were briefly handled and then returned to the home cage for $5 \mathrm{~d}$. Six days after restraint stress, mice underwent a habituation protocol $(3 \times 4$ min exposures) to the FC chamber to habituate them to the novel context, as described above. Seven days after restraint stress and $24 \mathrm{~h}$ after the habituation, mice underwent auditory cued FC with 2 CS-US pairings, as described above. Freezing during the last minute of exploration was used to determine SS/SR classifications, as this measure correlates with long-lasting extinction resistance and fear memory expression (Sillivan et al. 2017, 2019a). Mice were divided into thirds based on the \% freezing during this final minute with the top third highest freezing group being classified as SS and the bottom third lowest freezing group being classified as SR. Extinction/recall with 30 tone presentations (60 sec intertrial interval) was performed in a context unique from training as described above. And again, all extinction and recall freezing data were normalized to the pretone individual freezing levels as described.

\section{RNA extraction and $q P C R$}

Total RNA from fresh frozen bilateral tissue punches was obtained using the miRVANA PARIS RNA extraction kit (Life Technologies), as previously reported (Rumbaugh et al. 2015; Sillivan et al. 2019b). cDNA libraries of miRNAs were created from $20 \mathrm{ng}$ of total RNA with the mirCURY LNA RT Kit (Qiagen). PCR reactions were performed using the miRCURY LNA SYBR Green PCR Kit and the following locked nucleic acid (LNA) SYBR green primers from Qiagen: mmu-miR-598-3p, assay ID: YP00205045; snord68, assay ID: YP00203911; and RNU5G, assay ID: YP00203908. Data were normalized to the housekeeping genes snord68 and RNU5G using the $\Delta \Delta \mathrm{C}_{\mathrm{t}}$ method (Livak and Schmittgen 2001).

\section{Quantitative mass spectrometry}

Mass spectrometry was performed at the Harvard Mass Spectrometry and Proteomics Resource Laboratory as previously described (Sillivan et al. 2019b) and data was mined from a quantitative mass spectrometry run on BLA tissue collected from male mice $30 \mathrm{~d}$ post-SELF training (Sillivan et al. 2019a). Candidate pro- teins were identified as those that had at least $0.5 \log _{2}$ fold change between treatment groups.

\section{Intra-amygdalar infusions}

Hairpin inhibitors directed against mmu-miR-598-3p or the nonmammalian miRNA cel-miR-67 were obtained from GE Dharmacon (Lafayette, CO) and injected bilaterally into the BLA (AP: $1.5 \mathrm{~mm}$, ML: $\pm 3.2 \mathrm{~mm}$ from bregma and DV: $-4.7 \mathrm{~mm}$ from the skull) as previously described (Young et al. 2016). The injection needle was left in place for $5 \mathrm{~min}$ after the infusion was complete. Inhibitors were reconstituted in water then prepared with jetPEI transfection reagent (Polyplus Transfection). One micro liter per hemisphere of $400 \mathrm{ng} / \mu \mathrm{L}$ was injected $28 \mathrm{~d}$ after FC, animals remained in the home cage for $2 \mathrm{~d}$, and then were tested for either remote fear memory expression, anxiety-like behavior, and/or sacrificed such that mir-598-3p levels could be measured via qPCR.

\section{Fluorescence in situ hybridization (FISH)}

Neuroanatomical localization of mir-598-3p was achieved with FISH. Expression analysis experiments to detect miRNAs were performed as described (Sillivan et al. 2019a) using LNA dual 5' - and 3 '- DIG-labeled probes against mir-598-3p or a scrambled negative control sequence (Exiqon). While both the scrambled and sense sequence are common controls for in situ hybridization, the scrambled sense is more appropriate for miRNAs because the $5^{\prime}$ and $3^{\prime}$ strands of a stem-loop structure can be expressed in certain tissues (Ro et al. 2007; Song et al. 2010). Sections were mounted with Prolong Gold Diamond antifade mounting media with DAPI (Thermo Fisher) and visualized on an Olympus fluorescent confocal microscope with $60 \times$ objective (Tokyo, Japan).

\section{Cell fractionation}

BLC tissue from naïve animals was dissected fresh and immediately separated into cytosol/nuclear and synaptosome fractions as previously described (Sillivan et al. 2019a). Each sample was pooled from four animals. RNA was extracted from each cellular fractions with the miRVANA PARIS kit as described above.

\section{Statistical analysis}

A Student's $t$-test was used to analyze the initial qPCR experiment validating the $\mathrm{FC}$-induced reduction relative to naïve. A one-way ANOVA was used to analyze mir-598-3p expression in each of the four (for female) or five (for male) groups analyzed at $30 \mathrm{~d}$, $7 \mathrm{~d}$, or $24 \mathrm{~h}$ after each behavioral manipulation. Two-way (FC only) or three-way (SEFL) repeated measures ANOVAs were used to analyze the effect of mir-598-3p inhibition on remote fear memory in FC mice and SEFL mice, respectively. Significant interactions were reported and analyzed with LSD post hoc tests were used for pairwise comparisons. Student's t-tests (FC only) and two-way ANOVAs (SEFL) were used to analyze anxiety-like behavior in the EPM, OFT, and ASR tests, respectively. LSD post hoc tests were used for pairwise comparisons.

\section{Acknowledgments}

We thank the Scripps Florida Genomics Core for sequencing services, Nripesh Prasad at the Genomic Services Laboratory at Hudson Alpha for sequencing services and data analysis, Adrian Reich and the Bioinformatics Core for data analysis, the Mouse Behavior core and Alicia Brantley for assistance and behavioral equipment, all members of the Miller and Rumbaugh Labs for their technical assistance and thoughtful discussions. This work was funded by grants from the National Institute of Mental Health MH105400 (C.A.M.), National Institute on Drug Abuse DA041469 (S.E.S.) and the Brain and Behavior Foundation-NARSAD Young Investigator Award (S.E.S.). 


\section{References}

Agarwal V, Bell GW, Nam JW, Bartel DP. 2015. Predicting effective microRNA target sites in mammalian mRNAs. Elife 4: e05005. doi:10 .7554/eLife.05005

Asok A, Leroy F, Rayman JB, Kandel ER. 2019. Molecular mechanisms of the memory trace. Trends Neurosci 42: 14-22. doi:10.1016/j.tins.2018.10 .005

Bobińska K, Szemraj J, Gałecki P, Talarowska M. 2016. The role of MMP genes in recurrent depressive disorders and cognitive functions. Acta Neuropsychiatr 28: 221-231. doi:10.1017/neu.2015.72

Bowers ME, Ressler KJ. 2015. An overview of translationally informed treatments for posttraumatic stress disorder: animal models of Pavlovian fear conditioning to human clinical trials. Biol Psychiatry 78: E15-E27. doi:10.1016/j.biopsych.2015.06.008

Brewin CR. 2015. Re-experiencing traumatic events in PTSD: new avenues in research on intrusive memories and flashbacks. Eur J Psychotraumatol 6: 27180. doi:10.3402/ejpt.v6.27180

Cohen JL, Ata AE, Jackson NL, Rahn EJ, Ramaker RC, Cooper S, Kerman IA, Clinton SM. 2017. Differential stress induced c-Fos expression and identification of region-specific miRNA-mRNA networks in the dorsal raphe and amygdala of high-responder/low-responder rats. Behav Brain Res 319: 110-123. doi:10.1016/j.bbr.2016.11.015

Dias BG, Goodman JV, Ahluwalia R, Easton AE, Andero R, Ressler KJ. 2014. Amygdala-dependent fear memory consolidation via miR-34a and Notch signaling. Neuron 83: 906-918. doi:10.1016/j.neuron.2014.07 .019

Filipowicz W, Bhattacharyya SN, Sonenberg N. 2008. Mechanisms of post-transcriptional regulation by microRNAs: are the answers in sight? Nat Rev Genet 9: 102-114. doi:10.1038/nrg2290

Gale GD, Anagnostaras SG, Godsil BP, Mitchell S, Nozawa T, Sage JR, Wiltgen B, Fanselow MS. 2004. Role of the basolateral amygdala in the storage of fear memories across the adult lifetime of rats. J Neurosci 24: 3810-3815. doi:10.1523/JNEUROSCI.4100-03.2004

Gao J, Wang WY, Mao YW, Gräff J, Guan JS, Pan L, Mak G, Kim D, Su SC, Tsai LH. 2010. A novel pathway regulates memory and plasticity via SIRT1 and miR-134. Nature 466: 1105-1109. doi:10.1038/nature09271

Gebert LFR, MacRae IJ. 2019. Regulation of microRNA function in animals. Nat Rev Mol Cell Biol 20: 21-37. doi:10.1038/s41580-018-0045-7

Gisquet-Verrier P, Le Dorze C. 2019. Post traumatic stress disorder and substance use disorder as two pathologies affecting memory reactivation: implications for new therapeutic approaches. Front Behav Neurosci 13: 26. doi:10.3389/fnbeh.2019.00026

Griggs EM, Young EJ, Rumbaugh G, Miller CA. 2013. MicroRNA-182 regulates amygdala-dependent memory formation. J Neurosci 33: 17341740. doi:10.1523/JNEUROSCI.2873-12.2013

Haramati S, Navon I, Issler O, Ezra-Nevo G, Gil S, Zwang R, Hornstein E, Chen A. 2011. MicroRNA as repressors of stress-induced anxiety: the case of amygdalar miR-34. J Neurosci 31: 14191-14203. doi:10.1523/ JNEUROSCI.1673-11.2011

Hayashi ML, Choi SY, Rao BS, Jung HY, Lee HK, Zhang D, Chattarji S, Kirkwood A, Tonegawa S. 2004. Altered cortical synaptic morphology and impaired memory consolidation in forebrain- specific dominant-negative PAK transgenic mice. Neuron 42: 773-787. doi:10 $.1016 /$ j.neuron.2004.05.003

Hotulainen P, Hoogenraad CC. 2010. Actin in dendritic spines: connecting dynamics to function. J Cell Biol 189: 619-629. doi:10.1083/jcb .201003008

Issler O, Haramati S, Paul ED, Maeno H, Navon I, Zwang R, Gil S, Mayberg HS, Dunlop BW, Menke A, et al. 2014. MicroRNA 135 is essential for chronic stress resiliency, antidepressant efficacy, and intact serotonergic activity. Neuron 83: 344-360. doi:10.1016/j.neuron.2014 .05 .042

Jaksic N, Margetic BA, Marcinko D. 2017. Comorbid depression and suicide ideation in patients with combat-related PTSD: the role of temperament, character, and trait impulsivity. Psychiatr Danub 29: 51-59. doi:10 $.24869 /$ psyd.2017.51

Karagkouni D, Paraskevopoulou MD, Chatzopoulos S, Vlachos IS, Tastsoglou S, Kanellos I, Papadimitriou D, Kavakiotis I, Maniou S, Skoufos G, et al. 2018. DIANA-TarBase v8: a decade-long collection of experimentally supported miRNA-gene interactions. Nucleic Acids Res 46: D239-D245. doi:10.1093/nar/gkx1141

Kasai H, Fukuda M, Watanabe S, Hayashi-Takagi A, Noguchi J. 2010. Structural dynamics of dendritic spines in memory and cognition. Trends Neurosci 33: 121-129. doi:10.1016/j.tins.2010.01.001

Konopka W, Kiryk A, Novak M, Herwerth M, Parkitna JR, Wawrzyniak M, Kowarsch A, Michaluk P, Dzwonek J, Arnsperger T, et al. 2010. MicroRNA loss enhances learning and memory in mice. J Neurosci 30: 14835-14842. doi:10.1523/JNEUROSCI.3030-10.2010

Kozomara A, Birgaoanu M, Griffiths-Jones S. 2019. miRBase: from microRNA sequences to function. Nucleic Acids Res 47: D155-D162. doi:10.1093/nar/gky1141
Levy AD, Omar MH, Koleske AJ. 2014. Extracellular matrix control of dendritic spine and synapse structure and plasticity in adulthood. Front Neuroanat 8: 116. doi:10.3389/fnana.2014.00116

Lin Q, Wei W, Coelho CM, Li X, Baker-Andresen D, Dudley K, Ratnu VS, Boskovic Z, Kobor MS, Sun YE, et al. 2011. The brain-specific microRNA miR-128b regulates the formation of fear-extinction memory. Nat Neurosci 14: 1115-1117. doi:10.1038/nn.2891

Livak KJ, Schmittgen TD. 2001. Analysis of relative gene expression data using real-time quantitative PCR and the 2(-Delta Delta C(T)) method. Methods 25: 402-408. doi:10.1006/meth.2001.1262

Mannironi C, Biundo A, Rajendran S, De Vito F, Saba L, Caioli S, Zona C, Ciotti T, Caristi S, Perlas E, et al. 2018. miR-135a regulates synaptic transmission and anxiety-like behavior in amygdala. Mol Neurobiol 55: 3301-3315. doi:10.1007/s12035-017-0564-9

Mantzur L, Joels G, Lamprecht R. 2009. Actin polymerization in lateral amygdala is essential for fear memory formation. Neurobiol Learn Mem 91: 85-88. doi:10.1016/j.nlm.2008.09.001

Martin CG, Kim H, Yun S, Livingston W, Fetta J, Mysliwiec V, Baxter T, Gill JM. 2017. Circulating miRNA associated with posttraumatic stress disorder in a cohort of military combat veterans. Psychiatry Res 251: 261265. doi:10.1016/j.psychres.2017.01.081

McEwen BS. 2007. Physiology and neurobiology of stress and adaptation: central role of the brain. Physiol Rev 87: 873-904. doi:10.1152/physrev 00041.2006

Meydan C, Shenhar-Tsarfaty S, Soreq H. 2016. MicroRNA regulators of anxiety and metabolic disorders. Trends Mol Med 22: 798-812. doi:10 .1016/j.molmed.2016.07.001

Michopoulos V, Powers A, Gillespie CF, Ressler KJ, Jovanovic T. 2017. Inflammation in fear- and anxiety-based disorders: PTSD, GAD, and beyond. Neuropsychopharmacology 42: 254-270. doi:10.1038/npp.2016 .146

Muthusamy B, Selvan LDN, Nguyen TT, Manoj J, Stawiski EW, Jaiswal BS, Wang W, Raja R, Ramprasad VL, Gupta R, et al. 2017. Next-generation sequencing reveals novel mutations in X-linked intellectual disability. OMICS 21: 295-303. doi:10.1089/omi.2017.0009

Novaes LS, Dos Santos NB, Perfetto JG, Goosens KA, Munhoz CD. 2018 Environmental enrichment prevents acute restraint stress-induced anxiety-related behavior but not changes in basolateral amygdala spine density. Psychoneuroendocrinology 98: 6-10. doi:10.1016/j.psyneuen .2018.07.031

Perez-Martinez L, Jaworski DM. 2005. Tissue inhibitor of metalloproteinase- 2 promotes neuronal differentiation by acting as an anti-mitogenic signal. J Neurosci 25: 4917-4929. doi:10.1523/ JNEUROSCI.5066-04.2005

Ramakers GJ. 2002. Rho proteins, mental retardation and the cellular basis of cognition. Trends Neurosci 25: 191-199. doi:10.1016/S0166-2236(00) 02118-4

Riancho J, Vázquez-Higuera JL, Pozueta A, Lage C, Kazimierczak M, Bravo M, Calero M, Gonalezalez A, Rodriguez E, Lleo A, et al. 2017. MicroRNA profile in patients with Alzheimer's disease: analysis of miR-9-5p and miR-598 in raw and exosome enriched cerebrospinal fluid samples. $J$ Alzheimers Dis 57: 483-491. doi:10.3233/JAD-161179

Ro S, Park C, Young D, Sanders KM, Yan W. 2007. Tissue-dependent paired expression of miRNAs. Nucleic Acids Res 35: 5944-5953. doi:10.1093/ nar/gkm641

Rodrigues SM, Schafe GE, LeDoux JE. 2004. Molecular mechanisms underlying emotional learning and memory in the lateral amygdala. Neuron 44: 75-91. doi:10.1016/j.neuron.2004.09.014

Rumbaugh G, Sillivan SE, Ozkan ED, Rojas CS, Hubbs CR, Aceti M, Kilgore M, Kudugunti S, Puthanveettil SV, Sweatt JD, et al. 2015. Pharmacological selectivity within class I histone deacetylases predicts effects on synaptic function and memory rescue. Neuropsychopharmacology 40: 2307-2316. doi:10.1038/npp.2015.93

Sillivan SE, Joseph NF, Jamieson S, King ML, Chevere-Torres I, Fuentes I, Shumyatsky GP, Brantley AF, Rumbaugh G, Miller CA. 2017. Susceptibility and resilience to posttraumatic stress disorder-like behaviors in inbred mice. Biol Psychiatry 82: 924-933. doi:10.1016/ .biopsych.2017.06.030

Sillivan SE, Jamieson S, de Nijs L, Jones M, Snijders C, Klengel T, Joseph NF, Krauskopf J, Kleinjans J, Vinkers $\mathrm{CH}$, et al. 2019a. MicroRNA regulation of persistent stress-enhanced memory. Mol Psychiatry doi:10.1038/ s41380-019-0432-2

Sillivan SE, Jones ME, Jamieson S, Rumbaugh G, Miller CA. 2019b. Bioinformatic analysis of long-lasting transcriptional and translational changes in the basolateral amygdala following acute stress. PLoS One 14: e0209846. doi:10.1371/journal.pone.0209846

Smart FM, Halpain S. 2000. Regulation of dendritic spine stability. Hippocampus 10: 542-554. doi:10.1002/1098-1063(2000)10:5<542:: AID-HIPO4>3.0.CO;2-7

Song R, Ro S, Yan W. 2010. In situ hybridization detection of microRNAs. Methods Mol Biol 629: 287-294. doi:10.1007/978-1-60761-657-3_18 
Volk N, Paul ED, Haramati S, Eitan C, Fields BK, Zwang R, Gil S, Lowry CA, Chen A. 2014. MicroRNA-19b associates with Ago2 in the amygdala following chronic stress and regulates the adrenergic receptor $\beta 1$. J

Neurosci 34: 15070-15082. doi:10.1523/JNEUROSCI.0855-14.2014

Xie L, Chen J, Ding YM, Gui XW, Wu LX, Tian S, Wu W. 2019. MicroRNA-26a-2 maintains stress resiliency and antidepressant efficacy by targeting the serotonergic autoreceptor HTR1A. Biochem Biophys Res Commun 511: 440-446. doi:10.1016/j.bbrc.2019.02.078

Yang G, Pan F, Gan WB. 2009. Stably maintained dendritic spines are associated with lifelong memories. Nature 462: 920-924. doi:10.1038/ nature08577

Young EJ, Blouin AM, Briggs SB, Sillivan SE, Lin L, Cameron MD, Rumbaugh G, Miller CA. 2016. Nonmuscle myosin IIB as a therapeutic target for the prevention of relapse to methamphetamine use. $\mathrm{Mol}$ Psychiatry 21: 615-623. doi:10.1038/mp.2015.103

Zannas AS, West AE. 2014. Epigenetics and the regulation of stress vulnerability and resilience. Neuroscience 264: 157-170. doi:10.1016/j .neuroscience.2013.12.003
Zelikowsky M, Hersman S, Chawla MK, Barnes CA, Fanselow MS. 2014. Neuronal ensembles in amygdala, hippocampus, and prefrontal cortex track differential components of contextual fear. J Neurosci 34: 84628466. doi:10.1523/JNEUROSCI.3624-13.2014

Zhang Y, Su Z, Liu HL, Li L, Wei M, Ge DJ, Zhang ZJ. 2018. Effects of miR-26a-5p on neuropathic pain development by targeting MAPK6 in in CCI rat models. Biomed Pharmacother 107: 644-649. doi:10.1016/j .biopha.2018.08.005

Zhou J, Nagarkatti P, Zhong Y, Ginsberg JP, Singh NP, Zhang J, Nagarkatti M. 2014. Dysregulation in microRNA expression is associated with alterations in immune functions in combat veterans with post-traumatic stress disorder. PLoS One 9: e94075. doi:10.1371/journal .pone.0094075

Received March 19, 2019; accepted in revised form June 10, 2019. 


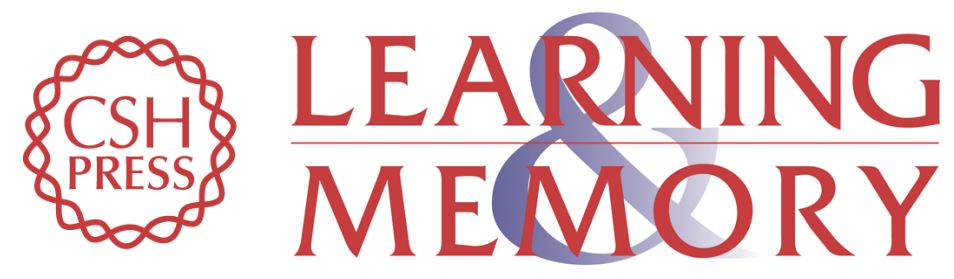

\section{microRNA mir-598-3p mediates susceptibility to stress enhancement of remote fear memory}

Meghan E. Jones, Stephanie E. Sillivan, Sarah Jamieson, et al.

Learn. Mem. 2019, 26:

Access the most recent version at doi:10.1101/Im.048827.118

\section{Supplemental http://learnmem.cshlp.org/content/suppl/2019/08/05/26.9.363.DC1 Material}

References This article cites 52 articles, 8 of which can be accessed free at: http://learnmem.cshlp.org/content/26/9/363.full.html\#ref-list-1

Creative This article is distributed exclusively by Cold Spring Harbor Laboratory Press for the Commons first 12 months after the full-issue publication date (see

License http://learnmem.cshlp.org/site/misc/terms.xhtml). After 12 months, it is available under a Creative Commons License (Attribution-NonCommercial 4.0 International), as described at http://creativecommons.org/licenses/by-nc/4.0/.

Email Alerting Receive free email alerts when new articles cite this article - sign up in the box at the Service top right corner of the article or click here. 